\title{
PENERAPAN NILAI-NILAI KEUSAHAWANAN DALAM PEMBELAJARAN BERASASKAN STUDIO DI UNIVERSITI MALAYSIA KELANTAN
}

\author{
KHAIRUL AZHAR MAT DAUD* \\ AHMAD RASDAN ISMAIL** \\ AHAMAD TARMIZI AZIZAN ${ }^{* * *}$ \\ MOHAMAD SYUKRAN KAMAL RUZZAMAN****
}

\begin{abstract}
Abstrak
Pembelajaran berasaskan studio merupakan pendekatan pembelajaran yang menekankan kepada pencapaian hasil kerja pelajar. Pembelajaran ini adalah berorientasikan kepada pelajar. Pelajar akan diberi peluang untuk merancang dan seterusnya membangunkan projek yang dirancang. Perlaksanaan projek akan dipantau oleh pensyarah yang bertindak sebagai fasilitator. Bagi memperkasakan lagi konsep pembelajaran berasaskan studio ini, maka unsur-unsur kemahiran insaniah perlu dipertingkatkan. Melalui kaedah pembelajaran di abad ke 21 ini, ciri-ciri keusahawanan seperti kemahiran berkomunikasi, kemahiran merancang, kemahiran bekerja dalam kumpulan serta sifat-sifat keusahawanan seperti cekal, rajin, kuat bekerja, amanah, kuat berusaha dan sebagainya perlu diterapkan dalam diri setiap pelajar. Melalui gabungan antara ciri-ciri kemahiran insaniah dan ciri-ciri keusahawanan ini, maka satu kaedah pembelajaran berasaskan studio dan berorientasikan pelajar telah dilaksanakan. Berdasarkan kepada kajian yang dijalankan, adalah didapati bahawa kaedah pembelajaran berasaskan usahawan ini telah berupaya meningkatkan tahap kemahiran insaniah pelajar serta memotivasikan pelajar.
\end{abstract}

Kata Kunci: Pembelajaran, Studio, Fasilitator, Keusahawanan, Kemahiran Insaniah

* PhD, Timbalan Dekan di Fakulti Teknologi Kreatif dan Warisan, Universiti Malaysia Kelantan

** Prof. Madya dan Ketua Unit Pengurusan Persekitaran, Keselamatan Dan Kesihatan Pekerjaan di Universiti Malaysia Kelantan.

*** Pensyarah Kanan di Fakulti Teknologi Kreatif dan Warisan, Universiti Malaysia Kelantan

**** Pensyarah di Fakulti Teknologi Kreatif dan Warisan, Universiti Malaysia Kelantan

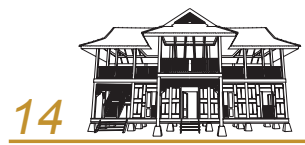




\begin{abstract}
Studio-based learning (SBL) is a learning approach that emphasizes on the achievement of students' works. SBL is student-oriented. Students will be given the opportunity to plan and develop the project. The project implementation will be monitored by the lecturer acting as a facilitator. To enhance studio-based learning concept, the elements of soft skills need to be enhanced. Aligned with the 21st century learning, entrepreneurial traits such as communication, planning and teamwork skills as well as entrepreneurial attributes such as perseverance, dilligent, trustworthy, and hardworking should be instilled in every student. Through a combination of the characteristics of soft skills and entrepreneurial, then a studiobased learning method and student-oriented have been implemented. Based on the study, it was found that the method of entrepreneur-based learning (EBL) has been able to raise the level of students' soft skills and motivate students.
\end{abstract}

Keywords: Learning, Studio, Facilitator, Entrepreneurial, soft skills.

* PhD, Timbalan Dekan di Fakulti Teknologi Kreatif dan Warisan, Universiti Malaysia Kelantan

** Prof. Madya dan Ketua Unit Pengurusan Persekitaran, Keselamatan Dan Kesihatan Pekerjaan di Universiti Malaysia Kelantan.

*** Pensyarah Kanan di Fakulti Teknologi Kreatif dan Warisan, Universiti Malaysia Kelantan

**** Pensyarah di Fakulti Teknologi Kreatif dan Warisan, Universiti Malaysia Kelantan 


\subsection{Pengenalan}

Modul Pembangunan Kemahiran Insaniah untuk Intitusi Pengajian Tinggi Malaysia (2006) menyatakan bahawa sistem pendidikan yang diamalkan boleh dianggap berjaya sekiranya kemahiran kognitif dan kemahiran psikomotor berjaya diterap secara bersepadu dalam proses pembelajaran yang dijalankan. Pembelajaran berasaskan projek atau pembelajaran berorientasikan pelajar adalah merupakan konsep pembelajaran yang banyak mengaplikasikan teori konstruktif. Pelajar mendapat ilmu pengetahuan melalui pengalaman dan aktiviti ketika melaksanakan projek yang dijalankan. Kebanyakan projek yang dirangka akan dijalankan oleh pelajar semasa berada di institusi pengajian. Projek yang dirancang adalah berkisarkan kepada pembangunan produk atau pelaksanaan tugasan dalam bentuk dokumentasi (Tan, S. T, Ng, \& Ng, C. K. F., 2010). Projek yang diberikan kepada pelajar akan dirangka dengan teliti agar proses pelaksanaan projek nanti berupaya untuk merangkumi keseluruhan kurikulum yang telah ditetapkan. Malahan, ada juga projek yang dirangka mengatasi ketetapan kurikulum sesuatu kursus.

Walaubagaimanapun, kebanyakan pembelajaran berorientasikan projek atau pembelajaran berorientasikan masalah tidak menekankan kepada realiti kehidupan sebenar. Pelajar masih lagi belajar dalam fenomena yang lama. Pelajar masih lagi terikat dengan sempadan tembok institusi, kelas dan sebagainya. Kaedah pembelajaran berorientasikan projek atau pembelajaran berorientasikan masalah ini hanya akan melahirkan pelajar yang mempunyai tahap kemahiran insaniah yang tinggi seperti kemahiran berkomunikasi, kemahiran berfikir, kemahiran membuat keputusan dan sebagainya, walaubagaimanapun ianya tidak dapat melahirkan pelajar yang mempunyai ciri-ciri keusahawanan yang tinggi seperti keazaman yang tinggi, sanggup berkorban apa sahaja, sanggup menghadapi sebarang risiko, sanggup bekerja tanpa mengenal erti penat lelah dan pelbagai lagi ciri keusahawanan yang sepatutnya perlu diterapkan ke dalam diri pelajar di institusi pengajian tinggi.

Oleh itu, satu pendekatan pembelajaran berasaskan kepada ciri-ciri keusahawanan dalam usaha untuk memperkasakan kaedah pembelajaran berasaskan projek dan pembelajaran berasaskan masalah, maka kaedah pembelajaran berasaskan usahawan (PBU) telah diperkenalkan dan dilaksanakan di Fakulti Teknologi Kreatif Dan Warisan.

Kaedah pembelajaran berasaskan usahawan (PBU) ini merupakan usaha untuk melahirkan pelajar yang mempunyai tahap kemahiran insaniah yang tinggi seperti kemahiran berkomunikasi, kemahiran merancang, kemahiran untuk membuat keputusan serta mempunyai ciri-ciri seorang usahawan unggul seperti cekal, tabah, sanggup berhadapan dengan risiko, keazaman diri yang tinggi dan sebagainya. Gabungan antara ciri kemahiran insaniah dan ciri-ciri keusahawanan dalam diri pelajar adalah amat penting bagi melahirkan serta menyediakan pelajar dengan cabaran abad ke 21 dan menyediakan pelajar dengan pekerjaan masa hadapan (Mohd Zahari, 2010). 
Walaubagaimanapun, berasaskan kepada laporan daripada Majlis Penasihat Ekonomi Kebangsaan (National Economic Advisory Council-NEAC) dalam Model Ekonomi Baru (New Economic Model-NEM), pada tahun 2008 sahaja terdapat satu pertiga daripada graduan institusi pengajian tinggi awam yang tidak bekerja selepas bergraduan lebih daripada enam bulan (NEAC, 2010). Model ekonomi baru (NEM) yang diumumkan oleh perdana menteri Malaysia pada bulan Mac 2010 telah meletakkan keusahawanan sebagai komponen utama untuk memacu ekonomi Negara ke tahap yang lebih baik dan membanggakan. Oleh itu, kerajaan telah mengenalpasti bahawa sumber utama untuk menghasilkan usahawan pada masa hadapan perlulah bermula di universiti. Walaubagaimanapun, berdasarkan kepada laporan timbalan menteri pengajian tinggi Malaysia, didapati hanya $2.4 \%$ sahaja graduan yang menjadi usahawan selepas bergraduasi. Angka ini sangat kecil jika dibandingkan dengan aspirasi Malaysia untuk menjadi sebuah negara maju menjelang 2020 (Azlan, 2009).

Sehubungan dengan itu, bagi menyokong hasrat kerajaan untuk melahirkan usahawan dalam kalangan graduan IPTA, maka satu kaedah Pembelajaran Berasaskan Usahawan (PBU) yang disepadukan dalam Pembelajaran Berasaskan Studio telah dilaksanakan. Kajian mengenai keberkesanan kaedah Pembelajaran Berasaskan Usahawan (PBU) ini telah dijalankan di Fakulti Teknologi Kreatif dan Warisan, Universiti Malaysia Kelantan.

\subsection{Pembelajaran Berasaskan Usahawan (PBU).}

Pembelajaran Berasaskan Usahawan terhasil daripada penambahbaikan kepada kaedah pembelajaran berasaskan projek. Tujuan pembelajaran berasaskan projek adalah bagi meningkatkan tahap kemahiran insaniah pelajar. Walaubagaimanapun, bagi menyediakan pelajar kepada pekerjaan dimasa hadapan, ciri-ciri yang lebih tinggi daripada kemahiran insaniah adalah amat diperlukan. Oleh itu, ciri-ciri usahawan seperti cekal, keazaman, tabah, sanggup menghadapi sebarang risiko dan sebagainya adalah juga dilihat amat penting. Gabungan antara ciri-ciri kemahiran insaniah dan ciri-ciri usahawan adalah dilihat amat penting dan perlu diterapkan dalam kalangan pelajar di abad ke 21 ini. Ahamad Tarmizi, Abd Aziz \& Fauzi (2010) menyatakan bahawa usaha melahirkan graduan dalam bidang keusahawanan telah dilaksanakan oleh beberapa insitusi pengajian tinggi di Malaysia sejak tahun 1997. Usaha ini dilaksanakan menerusi penawaran kursus-kursus keusahawanan dengan pemberatan 2 hingga 3 kredit menerusi aktiviti kurikulum tambahan seperti kelab keusahawanan, students in free enterprise (SIFE), minggu perniagaan, simposium, seminar, pertandingan rancangan perniagaan dan sebagainya (Dahlan, 2009). Namun, usaha ini kurang membuahkan hasil kerana kebanyakan Institusi Pengajian Tinggi (IPT) tidak jelas dengan objektif yang hendak dicapai dalam pendidikan keusahawanan (Ahamad Tarmizi, Abd Aziz \& Fauzi, 2010).

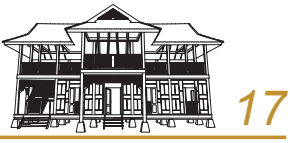


Pembelajaran Berasaskan Usahawan adalah merupakan kaedah pembelajaran yang mengabungkan konsep pembelajaran berorientasikan projek dan berupaya untuk menerapkan ciri-ciri kemahiran insaniah serta ciri-ciri usahawan dalam pembelajaran pelajar. Pembelajaran Berasaskan Usahawan (PBU) adalah didapati amat sesuai untuk diterapkan kedalam Pembelajaran Berasaskan Studio (PBS).

Didalam PBS, pelajar akan dibekalkan dengan masalah atau projek untuk dibangunkan. Pelajar dibenarkan untuk merancang dan merangka projek mereka dan perlu mendapat kelulusan daripada pensyarah yang juga akan bertindak sebagai fasilitator. Pelajar seterusnya akan melaksanakan kerjakerja pembangunan projek sebagaimana yang telah dirangka dan dirancang. Pelajar akan melaksanakan projek mereka samada secara individu atau secara berkumpulan. Ahamad Tarmizi, Abd Aziz \& Fauzi (2010) menyatakan bahawa pelajar berupaya menjana kemahiran "hands-on", daya kreativiti, kritis, dan inovatif menerusi penerokaan pengalaman sebenar melaksanakan pembangunan projek di dalam studio (bengkel / makmal - di universiti / rumah / industri). Hal ini secara tidak langsung mewujudkan suasana pembelajaran "learning by doing" (action learning/learning thru experience) yang berupaya untuk menjana pembangunan domain kognitif, afektif, psikomotor dan kemahiran insaniah pelajar secara holistik. Melalui kaedah ini, pelajar akan dapat menguasai dan meningkatkan tahap kemahiran insaniah mereka seperti kemahiran berkomunikasi, berdiskusi, kemahiran merancang, kemahiran membuat keputusan dan sebagainya, tetapi ciri-ciri usahawan yang juga amat diperlukan dalam kehidupan yang penuh mencabar pada abad ke 21 ini tidak dapat diterapkan ke dalam diri pelajar tersebut.

Bagi merealisasikan hasrat kerajaan untuk melahirkan pelajar yang bukan sahaja mempunyai tahap kemahiran insaniah yang tinggi, tetapi juga mempunyai ciri-ciri usahawan unggul seperti keazaman yang tinggi, cekal, tabah, sanggup menghadapi risiko dan sebagainya, maka pembelajaran berasaskan usahawan adalah dilihat amat penting untuk diterapkan dalam kalangan pelajar.

PBU boleh dilaksanakan sekiranya perancangan yang rapi dilaksanakan. Dalam kajian ini, PBU telah dilaksanakan bagi kursus Rekabentuk Digital CVT 2122, dimana pelajar dikehendaki menubuhkan syarikat mengikut kumpulan masing-masing. Pelajar diagihkan kepada 23 kumpulan dimana setiap kumpulan secara puratanya terdiri daripada empat atau lima orang. Pelajar dikehendaki mendaftarkan syarikat yang hendak ditubuhkan melalui Suruhanjaya Syarikat Malaysia (SSM). Pendaftaran syarikat merupakan tugasan pertama pelajar yang mengikuti kursus Rekabentuk Digital. Pelajar akan belajar dalam kumpulan yang digerakkan melalui syarikat yang ditubuhkan. Aktiviti syarikat digerakkan oleh pelajar sendiri, dan setiap aktiviti serta halatuju awal syarikat yang dirangka adalah merangkumi keseluruhan kurikulum bagi kursus CVT 2122 Rekabentuk Produk. 


\subsection{Metodologi Kajian}

Kajian ini dijalankan ke atas pelajar ljazah Sarjana Muda Teknologi Kreatif tahun 2 yang mengambil kursus CVT 2122 Rekabentuk Digital. Terdapat 120 orang pelajar atau empat kelas yang terlibat dalam kajian ini. Populasi pelajar ini telah dibahagikan kepada 23 kumpulan kecil yang terdiri secara puratanya 4 atau 5 orang bagi setiap kumpulan. Kumpulan pelajar tersebut kemudiannya akan berbincang dan diminta untuk menubuhkan sebuah syarikat yang berasaskan kepada kerja-kerja percetakan, penerbitan dan kerja-kerja berasaskan teknologi kreatif seperti animasi, pengiklanan, perfileman dan sebagainya. Pelajar akan berbincang sesama mereka dan akan memutuskan nama syarikat mereka. Selepas itu, pelajar akan mendaftarkan syarikat mereka di Suruhanjaya Syarikat Malaysia (SSM).

Setiap syarikat yang didaftarkan oleh pelajar dibawah SSM kemudiannya akan membangunkan profil syarikat masing-masing. Profil syarikat adalah terdiri daripada latar belakang penubuhan syarikat, carta organisasi syarikat, laporan kewangan syarikat, misi dan visi syarikat, rancangan perniagaan syarikat, sijil pendaftaran syarikat dan pelbagai perkara yang berkaitan.

Tugasan pertama pelajar bagi kursus CVT 2122 Rekabentuk Digital ialah membangunkan logo syarikat. Logo syarikat akan dibangunkan dan dinilai secara individu. Proses pembangunan logo akan diterangkan oleh pensyarah yang bertindak sebagai fasilitator. Penerangan dan panduan awal diberikan kepada pelajar. Logo yang dibuat hendaklah berasaskan kepada nama syarikat yang diputuskan. Kemudian, pelajar akan membentangkan logo yang telah dibangunkan dalam syarikat masing-masing. Logo yang terbaik dalam kalangan mereka akan dipilih sebagai logo syarikat.

Tugasan kedua pula, ialah pembangunan komik digital. Setiap syarikat ditugaskan untuk membangunkan komik digital. Halatuju syarikat perlu dijelaskan oleh pensyarah agar pelajar dapat memahami objektif penubuhan syarikat ini. Tugasan pertama syarikat adalah membangunkan komik digital yang kemudiannya akan di muatnaik ke dalam perisian android. Melalui pengaplikasian android ini, akhirnya syarikat tersebut akan mendapat keuntungan. Selain daripada itu, penjanaan pendapatan daripada syarikat yang ditubuh juga dapat meningkatkan motivasi pelajar untuk terus belajar dalam bidang teknologi kreatif ini terutama yang berasaskan kepada kejuruteraan seni digital. Pelajar bukan sahaja akan dapat menjana keuntungan dari aspek material malahan juga dalam masa yang sama akan melalui proses Pembelajaran Berasaskan Usahawan (PBU).

Melalui kaedah ini, ciri-ciri keusahawanan seperti tabah, cekal, keazaman yang tinggi sanggup menghadapi sebarang risiko dan sebagainya dapat diterapkan ke dalam diri setiap pelajar. Melalui proses pembangunan komik digital ini, pelajar akan bekerja secara berkumpulan dan akan diterapkan dengan budaya korporat. Pelajar akan belajar dan bekerja secara bersungguh-sungguh untuk menyempurnakan tugasan mereka. 
Perlantikan CEO dalam kalangan mereka bagi setiap syarikat adalah penting. Setiap ketua atau dikenali sebagai CEO ini akan bertanggungjawab secara sepenuhnya dalam mengemudi syarikat masing-masing untuk mencapai objektif syarikat yang telah dirangka dan dirancang. Mesyuarat CEO dijalankan pada setiap minggu. Perjalanan mesyuarat dipantau oleh pensyarah yang bertindak sebagai ahli lembaga pengarah. Terdapat tiga orang pensyarah yang terlibat dalam kajian ini.

Pengagihan tugasan bagi setiap pelajar akan diputuskan oleh CEO dalam syarikat masing-masing. Terdapat beberapa kerja seperti pereka grafik, pembangunan cerita (story telling) naratif papan cerita (story board), pelakar grafik, pakar digital, strategi pemasaran dan sebagainya perlu diagihkan secara adil dan bijaksana oleh CEO yang dilantik. Mesyuarat secara berkala bagi setiap kumpulan juga adalah penting dan perlu dipantau oleh pensyarah selaku ahli lembaga pengarah agar setiap syarikat dapat melaksanakan tugasan mereka dengan lancar.

\subsection{Proses "Pitching"}

Komik yang sedang dibangunkan ini kemudiannya akan melalui proses saringan awal sebelum melalui proses "pitching" bersama dengan pihak MDEC dan ICC Incubator. Kerjasama antara pihak MDEC dan ICC incubator untuk membangunkan komik digital kedalam pengaplikasian android memberi kesan yang amat bermakna kepada pelajar. Melalui tinjauan awal yang dibuat, didapati kebanyakan pelajar menyatakan amat teruja dengan kehadiran pihak industri seperti MDEC dan ICC Inkubator dalam menjayakan halatuju syarikat. Pelajar menyatakan mereka menjadi sangat bersemangat dan bermotivasi untuk menyiapkan projek mereka kerana mereka sangat jelas dengan halatuju syarikat dan juga objektif yang hendak dicapai melalui kursus CVT2122 Rekabentuk Digital.

Proses saringan awal dibuat dihadapan semua syarikat, dimana setiap syarikat akan diberi masa selama 15 minit untuk mempersembahkan hasil kerja mereka, halatuju syarikat, anggaran masa untuk melaksanakan kerja dan sebagainya. Terdapat 23 syarikat yang melalui proses saringan awal ini. Daripada 23 syarikat ini, 10 syarikat yang terbaik akan dipilih oleh ahli lembaga pengarah yang tediri daripada 3 orang pensyarah. Syarikat yang terpilih ini akan diminta untuk melalui proses "pitching" bersama dengan MDEC dan ICT Inkubator untuk dipilih bagi proses pengaplikasian android. Pihak MDEC dan ICT Inkubator akan memilih 7 syarikat yang terbaik daripada 10 syarikat yang melalui proses "pitching" tersebut. 


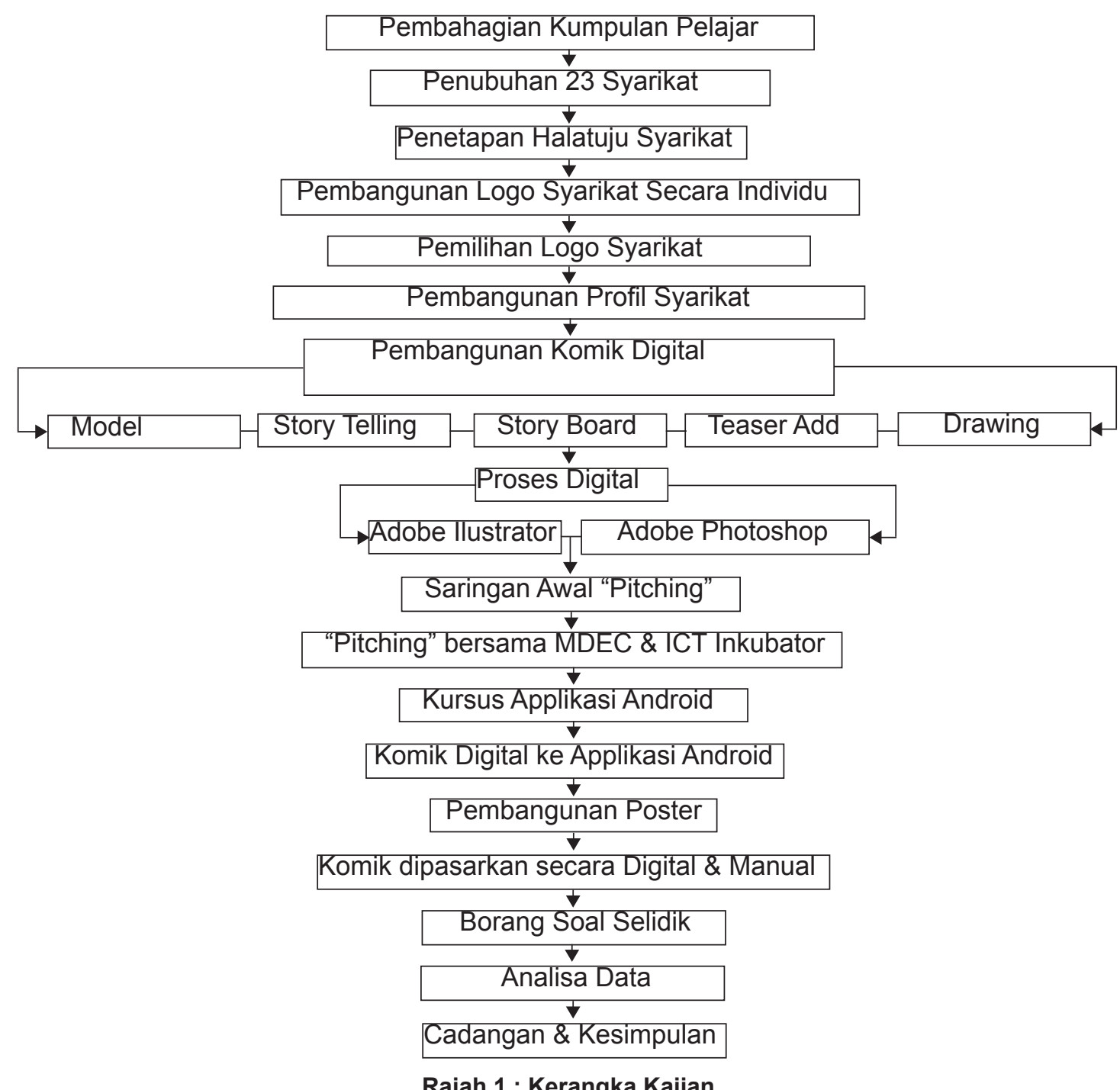




\subsection{Dapatan Kajian}

Setelah metodologi kajian ini dilaksanakan, maka kajian secara kualitatif melalui edaran borang soal selidik telah dijalankan. Borang soal selidik yang dibangunkan berdasarkan kepada objektif kajian yang dirangka. Borang soal selidik terbahagi kepada tiga bahagian utama iaitu:

\section{Bahagian A: Demografi Responden}

Bahagian B: Pengukuran Peningkatan Tahap Ciri-Ciri Usahawan Pelajar Bahagian C: Pengukuran Peningkatan Tahap Kemahiran Insaniah Pelajar

Instrumen kajian yang dibangunkan ini akan melalui proses kajian rintis, dimana nilai alpha cronbach akan dianalisis bagi melihat tahap kebolehpercayaan dan kesahan instrumen tersebut. Melalui kajian rintis yang dibuat, didapati nilai alpha cronbach, $\alpha=0.89$. Nilai ini adalah cukup tinggi dan disimpulkan bahawa instrumen kajian yang dibina adalah mempunyai tahap kebolehpercayaan dan kesahan yang tinggi.

Hasil dapatan kajian difokuskan terhadap analisis data-data yang di perolehi. Data-data ini di kumpul menggunakan kaedah soal selidik terhadap peningkatan tahap ciri-ciri usahawan pelajar, peningkatan tahap kemahiran insaniah pelajar dan kepentingan budaya korporat dalam proses pembelajaran. Semua soal selidik yang diagihkan dipulangkan semula sepenuhnya tetapi beberapa set terpaksa dikeluarkan kerana responden tidak menjawab penuh dan meragukan. Maklum balas yang dikumpulkan di analisis untuk meninjau peningkatan tahap ciri-ciri usahawan, peningkatan tahap kemahiran insaniah pelajar dan kepentingan budaya korporat dalam proses pembelajaran. Data yang diperolehi akan dianalisis dengan menggunakan perisian Statistical Package For Social Science (SPSS) versi 18 keluaran IBM. Data yang telah dianalisis dipersembahkan dalam bentuk kekerapan, peratusan, min dan sisihan piawai. 


\subsection{Analisis Ciri-Ciri Usahawan Pelajar}

Jadual 1: Keputusan ujian deskriptif terhadap tahap peningkatan ciri-ciri usahawan pelajar

\begin{tabular}{|c|c|c|c|c|c|c|}
\hline Bil & Item & $\mathbf{N}$ & Minimum & Maksimum & Min & $\begin{array}{r}\text { Sisihan } \\
\text { Piawai }\end{array}$ \\
\hline \multicolumn{7}{|c|}{ Setelah melalui proses Pembelajaran Berasaskan Usahawan $(\mathrm{PBU})$ ini saya rasa .......................... } \\
\hline 1 & ... tahap kecekalan dalam diri saya semakin meningkat. & 120 & 3 & 5 & 4.2 & 0.75147 \\
\hline 2 & ... tahap ketabahan dalam diri saya semakin meningkat. & 120 & 3 & 5 & 4.3 & 0.643 \\
\hline 3 & ... tahap daya usaha saya semakin meningkat. & 120 & 3 & 5 & 4.4 & 0.66611 \\
\hline 4 & $\begin{array}{l}\text {... tahap Keazaman untuk melaksanakan sesuatu semakin } \\
\text { meningkat }\end{array}$ & 120 & 2 & 5 & 4.3 & 0.90377 \\
\hline 5 & ... sanggup menghadapi sebarang risiko. & 120 & 3 & 5 & 4.5 & 0.80961 \\
\hline 6 & ... lebih rajin daripada dulu. & 120 & 3 & 5 & 4.5 & 0.80961 \\
\hline 7 & ... sanggup bekerja tanpa mengira masa. & 120 & 2 & 5 & 4.4 & 0.92036 \\
\hline 8 & $\begin{array}{l}\text {...tidak ada lagi erti letih, penat dan lelah untuk mencapai } \\
\text { sesuatu kejayaan }\end{array}$ & 120 & 2 & 5 & 4.5 & 0.92582 \\
\hline 9 & $\begin{array}{l}\text {... sanggup berkorban apa saja untuk mencapai objektif } \\
\text { perniagaan yang telah dirangka. }\end{array}$ & 120 & 3 & 5 & 4.8 & 0.60252 \\
\hline 10 & $\begin{array}{l}\text {...secara keseluruhannya tahap ciri-ciri usahawan dalam diri } \\
\text { saya semakin meningkat. }\end{array}$ & 120 & 3 & 5 & 4.6 & 0.66611 \\
\hline & Tahap Ciri-Ciri Usahawan Secara Keseluruhan & 120 & 2.7 & 5 & 4.45 & 0.6844 \\
\hline
\end{tabular}

usahawan

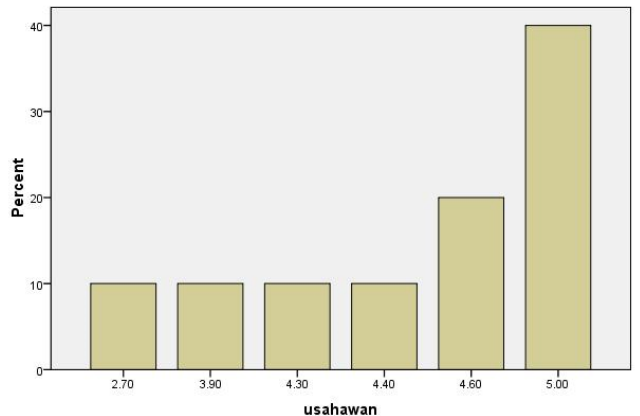

Rajah 2 : Carta Bar Peningkatan Ciri Usahawan Dalam Kalangan Pelajar 
Analisa yang dibuat menunjukkan bahawa nilai min bagi ciri-ciri usahawan pelajar adalah tinggi. Ini menunjukkan bahawa pendekatan PBU yang diapplikasikan dalam PBS bagi kursus CVT2122 Rekabentuk Studio adalah sangat berkesan $(\min =4.450, S D=.68440)$ untuk meningkatkan tahap ciri-ciri usahawan dalam kalangan pelajar

\subsection{Analisis Tahap Kemahiran Insaniah Pelajar}

Jadual 2: Keputusan ujian deskriptif terhadap tahap peningkatan kemahiran insaniah pelajar

\begin{tabular}{|c|c|c|c|c|c|c|}
\hline Bil & Item & $\mathbf{N}$ & $\underset{\mathbf{m}}{\text { Minimu }}$ & $\begin{array}{c}\text { Maksim } \\
\text { um }\end{array}$ & Min & $\begin{array}{l}\text { Sisihan } \\
\text { Piawai }\end{array}$ \\
\hline \multicolumn{7}{|c|}{ Setelah melalui proses Pembelajaran Berasaskan Usahawan (PBU) ini saya rasa ... } \\
\hline 1 & ...tahap keyakinan diri dalam diri saya semakin meningkat & 120 & 3 & 5 & 4.5 & 0.67363 \\
\hline 2 & ...tahap kemahiran berkomunikasi saya semakin meningkat & 120 & 2 & 5 & 4.4 & 0.92036 \\
\hline 3 & ... tahap kemahiran membuat keputusan saya semakin meningkat & 120 & 3 & 5 & 4.7 & 0.643 \\
\hline 4 & ... tahap kemahiran bekerja secara berkumpulan semakin meningkat & 120 & 3 & 5 & 4.7 & 0.643 \\
\hline 5 & ... tahap kemahiran mencari maklumat semakin meningkat & 120 & 3 & 5 & 4.7 & 0.643 \\
\hline 6 & ...tahap kemahiran untuk merancang semakin meningkat & 120 & 3 & 5 & 4.7 & 0.643 \\
\hline 7 & ... tahap kemahiran memimpin semakin meningkat. & 120 & 2 & 5 & 4.6 & 0.92036 \\
\hline 8 & ... tahap keyakinan diri saya semakin meningkat. & 120 & 2 & 5 & 4.6 & 0.92036 \\
\hline 9 & ... tahap kemahiran diskusi saya semakin meningkat. & 120 & 3 & 5 & 4.625 & 0.69889 \\
\hline 10 & $\begin{array}{l}\text {...secara keseluruhannya tahap kemahiran insaniah saya semakin } \\
\text { meningkat. }\end{array}$ & 120 & 1 & 6 & 4.5 & 1.38418 \\
\hline & Tahap Kemahiran Insaniah Secara Keseluruhan & 120 & 2.5 & 5 & 4.613 & 0.72102 \\
\hline
\end{tabular}




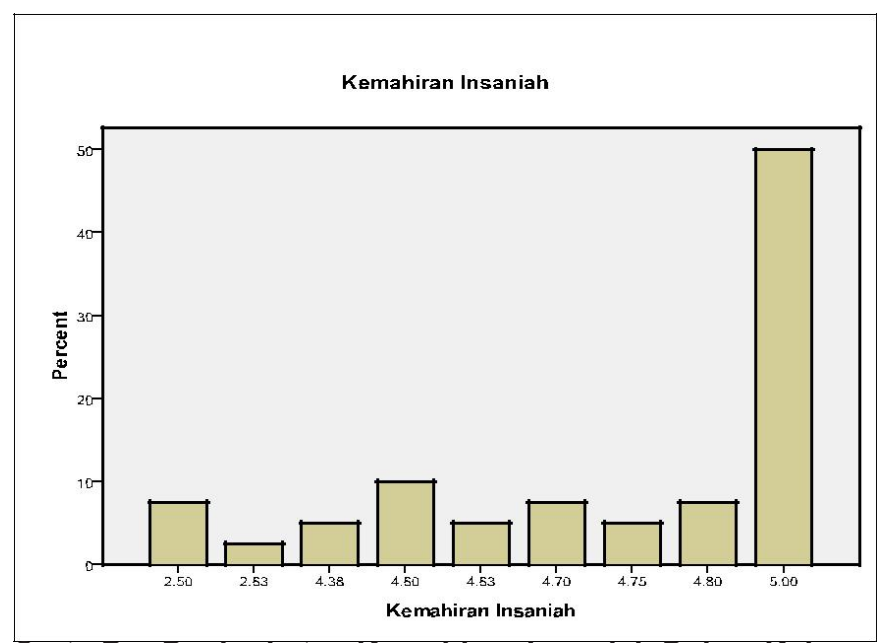

Rajah 3 : Carta Bar Peningkatan Kemahiran Insaniah Dalam Kalangan Pelajar

Analisa yang dibuat menunjukkan bahawa nilai min bagi tahap kemahiran insaniah pelajar adalah tinggi. Ini menunjukkan bahawa pendekatan PBU yang diaplikasikan dalam PBS bagi kursus CVT2122 Rekabentuk Studio adalah sangat berkesan $(\mathrm{min}=4.613 .000, \mathrm{SD}=.72102)$ untuk meningkatkan tahap kemahiran insaniah pelajar.

\subsection{Kesimpulan dan Penutup}

Dapatan kajian yang diperolehi menunjukkan bahawa ciri-ciri keusahawanan dapat dipertingkatkan melalui kaedah PBU yang diintegrasikan kedalam kaedah PBS. Modal insan yang mempunyai tahap kemahiran insaniah yang tinggi perlu diperkasakan dengan ciri-ciri usahawan yang unggul. Ciri usahawan yang unggul dapat membantu pelajar dalam menghadapi sebarang cabaran dalam realiti kehidupan sebenar semasa mengaplikasikan segala ilmu yang dipelajari semasa berada di menara gading. Kemahiran insaniah yang tinggi seperti kemahiran berkomunikasi, kemahiran merancang, kemahiran membuat keputusan dan sebagainya tidak akan dapat dimanipulasi dengan sebaik mungkin oleh seseorang pelajar sekiranya tidak mempunyai ciri usahawan unggul. Ciri usahawan unggul seperti tabah berusaha, cekal dalam menghadapi sebarang cabaran, tahap kesabaran yang tinggi dalam menghadapi sebarang dugaan, gigih berusaha ke arah kejayaan, tahap keazaman yang konsisten dan sebagainya perlulah diterap dan ditanam dengan kukuh ke dalam diri diri seseorang pelajar.

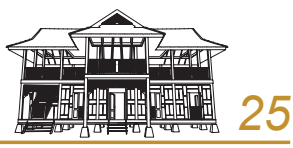


Pelajar akan menjadi lebih berjaya sekiranya ciri-ciri usahawan unggul ini dapat diterapkan kedalam diri pelajar. Ciri usahawan unggul seharusnya dapat memandu pelajar untuk memanipulasikan kemahiran insaniah yang ada dalam diri pelajar. Oleh itu, adalah diharapkan penyelidikan berkaitan dengan penerapan ciri-ciri usahawan dalam proses pembelajaran pelajar dapat dikaji dengan lebih mendalam agar unsur-unsur kemahiran insaniah dapat diaplikasikan oleh pelajar tanpa sebarang kompromi akibat dari konflik perasaan dalaman pelajar.

\section{Referances}

Azlan, A.B. (2009, November 17). Getting more grads to become entrepreneurs. The New Straits Times, p.B7

Ahamad Tarmizi Azizan, Ab. Aziz Shuaib dan Fauzi Ab Llah, (2010). Makyong Dua Indera: Ekplorasi Kreatif Menerusi Animasi.

Arifatul Husna, M.A., Zainol, B., Zakiyah, S., \& Adura, A. (2010). Predicting Entrepreneurial Intention Among Malay University Accounting Students in Malaysia . Unitar e-Journal. Retrieved July 24, 2010,

Caroline, V., \& Rémi, B. (2006). Developing an Entrepreneurial Spirit among engineering college students: what are the educational factors? In A. Fayolle and H. Klandt (eds.) International Entrepreneurship Education Issues and Newness. Retrieved September 20, 2013,

Dahlan, I., Hakimin, Y., dan Azwin, N. (2010). "The Relationship Between Tacit Knowledge and Entrepreneurial Intentions Among University Students", Entrepreneurial Education and Entrepreneurship in Malaysia : Book of Readings., Vol.1, p. 26-38.

Gilbert, D. (2010). Integrating Theory and Practice for Student Entrepreneurs: An Applied Learning Model. Journal of Enterprising Culture, 18(1). 83-106.

Hatten T.S., \& Ruhland, S.K. (1995). Student attitude toward entrepreneurship as affected by participation in an SBI program. Journal of Education for Business, 70(4), 224-227.

Jones, C. and English, J. (2010) "A Contemporary Approach To Entrepreneurship Education", Education + Training, Vol.46, No. 8/9, pp. 416-423

Anderson, L.M., \& Brown, W. (2006). Are engineers becoming more enterprising? A study of the potentials of entrepreneurship education. International Journal of Continuing Engineering Education and Life Long learning, 16(5), 355-365.

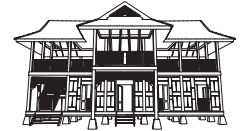


Mohd Dahlan Ibrahim, Ghazali Ahmad, Mohd Rafi Yaacob, (2010). Etrepreneurial Education and Entrepreneurship in Malaysia : Book of Readings., Vol.1. Kota Bharu : FKP, UMK.

Mohd Fairuz, R. (2006). Kesediaan Bakal Graduan Hotel dan Katering Politeknik Dalam Menceburi Bidang Keusahawanan Katering. [Unpublished master's project report). Universiti Tun Hussein Onn, Johor, Malaysia.

Mohd Nizam, A.R., Norhamidi, M., Dzuraidah A.W., Jaharah, A.G., Nishata Royan, R.R., \& Shahida Azura, M.A. (2009). Engineering Students towards Entrepreneurship Awareness. Seminar Pendidikan Kejuruteraan dan Alam Bina (PeKA'09). Retrieved June 10, 2010

Mohd Zahari, I. (2010). Developing Entrepreneurship Education: Empirical Findings from Malaysian Polytechnics. (Doctoral dissertation, The University of Hull, United Kingdom). Retrieved July 10, 2010

Nor Azizah Salleh, Siti Rahayah Ariffin Dan Musa Daia (2010). Penerapan Nilai Murni Melalui Pembelajaran-Kooperatif dalam Sains. Diperolehi daripada: Murni MJeulranluail PPeemndbiedliakjaanra 2n7-K(2o0o0p1e)r a4t7if -d 5a7lam Sains 47

Tan, S. T, Ng, and Ng, C. K. F. (2010) "A Problem- based Learning Approach to Entrepreneurship Education”, Education +Training, Vol. 48, No. 6, pp. 416-428

Verzat_Bachelet.pdf Fewer unemployed graduates expected. (2009, July 22). The New Straits Times, p.2. Galloway,

Wang, C.K, \& Wong P.K. (2004). Entrepreneurial interest of university students in Singapore. Technovation, 24(2), 163-172.

Yar Hamidi, D., Wennberg, K., \& Berglund, H. (2008). Creativity in Entrepreneurship Education. Journal of Small Business and Enterprise Development. 15(2), 304-320.

Zahariah M.Z, Amalina M.A., \& Erlane, K. G. (2010). Entrepreneurship Intention Among Malaysian Business Students. Canadian Social Science, 6(3),34-44.

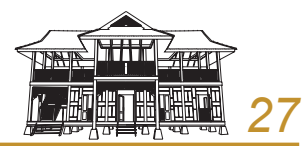

